\title{
Prevalence and risk factors of Toxoplasma gondii and Leishmania spp. infections in apparently healthy dogs in west Shewa zone, Oromia, Ethiopia
}

Endrias Zewdu Gebremedhin ${ }^{1 *}$, Edilu Jorga Sarba ${ }^{1}$, Getachew Kebebew Tola', Solomon Shiferaw Endalew², Lencho Megersa Marami², Asaminew Tesfaye Melkamsew ${ }^{3}$, Vincenzo Di Marco Lo Presti ${ }^{4}$ and Maria Vitale ${ }^{5}$

\begin{abstract}
Background: In urban settings, the presence of a high density of the human population and contact with domestic and/or stray animals such as dogs and cats can be risk factors for the transmission of zoonotic protozoa parasites. Toxoplasma gondii (T. gondii) and Leishmania spp. are zoonotic protozoon parasites with significant health burdens worldwide.

Methods: A cross-sectional study was used to investigate the antibody prevalence and risk factors of T. gondii and Leishmania spp. infections in 385 randomly selected dogs of Ambo, Bako, and Gojo towns of West Shewa Zone, Oromia regional state, Ethiopia. A questionnaire survey was administered to households to collect data on potential risk factors. Dog sera samples were assayed for T. gondii lgG antibodies using the direct agglutination test while Leishmania spp. specific antibodies tested using an indirect enzyme-linked immunosorbent assay (ELISA). Logistic regression was used for data analysis.

Results: Overall, T. gondii and Leishmania spp. infection seroprevalence was found to be $82.86 \%$ (95\% confidence interval (Cl): 78.71-86.49\%) and 92.47\% (95\% Cl: 89.36-94.90\%), respectively. Seropositivity for both T. gondii and Leishmania spp. was found in $82.58 \%$ of the dogs. None of the investigated factors were associated with Leishmania spp. seropositivity $(p>0.05)$. The seroprevalence of $T$. gondii was significantly different among the study towns $(p=$ 0.003). The risk of $T$. gondii infection was 2.71 times higher in adult dogs than juvenile dogs $(p=0.043)$. Dogs kept simultaneously with other domestic animals had increased odds of $T$. gondii seropositivity compared to those with no other domestic animals (Adjusted Odds ratio: 1.96, $p=0.021$ ). However, altitude, sex, breed, housing, feeding, educational level of head of the household, and dog's living area were not significantly associated with $T$. gondii seropositivity $(p>0.05)$.
\end{abstract}

\footnotetext{
* Correspondence: endrias.zewdu@gmail.com

'Department of Veterinary Sciences, Ambo University, School of Veterinary Medicine, P. O. Box 19, Ambo, Ethiopia

Full list of author information is available at the end of the article
}

(c) The Author(s). 2021 Open Access This article is licensed under a Creative Commons Attribution 4.0 International License, which permits use, sharing, adaptation, distribution and reproduction in any medium or format, as long as you give appropriate credit to the original author(s) and the source, provide a link to the Creative Commons licence, and indicate if changes were made. The images or other third party material in this article are included in the article's Creative Commons licence, unless indicated otherwise in a credit line to the material. If material is not included in the article's Creative Commons licence and your intended use is not permitted by statutory regulation or exceeds the permitted use, you will need to obtain permission directly from the copyright holder. To view a copy of this licence, visit http://creativecommons.org/licenses/by/4.0/ The Creative Commons Public Domain Dedication waiver (http://creativecommons.org/publicdomain/zero/1.0/) applies to the data made available in this article, unless otherwise stated in a credit line to the data. 
Conclusions: The high seropositivity and the simultaneous presence of antibodies of T. gondii and Leishmania spp. in dogs suggest the widespread nature of these parasites in the environment and the high potential of transmission to other animals and humans. Further epidemiological studies, isolation and molecular characterization of the parasites, and educational campaigns are suggested.

Keywords: Dogs, Ethiopia, Leishmania, Risk factors, Seroprevalence, T. Gondii

\section{Introduction}

Toxoplasmosis and leishmaniasis are important zoonotic diseases both caused by unicellular parasites. Toxoplasmosis is spread worldwide since T. gondii can infect almost all warm-blooded animals and humans and can be transmitted through many different routes [1]. Leishmaniasis is a vector-borne disease of great medical and veterinary importance in different geographic areas caused by different Leishmania spp. transmitted by sand fly vectors (Phlebotomus spp.). There are two major clinical forms of the disease in both humans and dogs, cutaneous (CL) and visceral leishmaniasis (VL, also known as Kala-azar) [2]. Leishmaniases are neglected tropical and subtropical diseases endemic to 98 countries worldwide [3] including Ethiopia [4]. Visceral leishmaniasis (VL) affects about 12 million people worldwide with almost 0.5 million new cases of VL and 350 million people are at risk of infection each year [5]. Ethiopia, India, Bangladesh, Sudan, South Sudan, and Brazil are countries with a high prevalence of visceral leishmaniasis (90\% of cases) [3]. Canine Leishmaniasis (Can L) is a very serious disease when remains untreated and can be a focus of transmission to other dogs or humans particularly in endemic areas where the sandflies are present. Canine leishmaniasis is an endemic disease in more than 70 countries and is a common disease in the Mediterranean region. However, many cases have been reported in non-endemic areas, like the United Kingdom, Germany, and Poland, where this disease is considered exotic [6] The cases in North-European countries are probably related to the owners' traveling with their dogs exposed to competent insect vectors through endemic regions. In addition, non-vectorial transmission between dogs including infection through transfused blood products from infected donors, transplacental and venereal transmission have been reported [7].

Upon parasite transmission, some dogs can control the infection for many years, without the appearance of clinical signs while other dogs may display an acute evolution and severe disease, or progressive course that leads to death if proper management and therapy are not adopted. The management of CanL is being performed recently using prophylactic measures in healthy dogs such as using insecticides impregnated collars [8].

In Ethiopia, there are several foci of Leishmania spp. infections in humans with frequent outbreaks leading to over 7000 and 50,000 new cases of visceral (VL) and cutaneous leishmaniasis (CL) per year, respectively [9]. This has contributed to their identification as a major public health concern. Leishmaniasis, however, remains one of the most overlooked tropical diseases [10]. Many infected animals are asymptomatic in endemic areas, and their role in infection transmission is mainly unknown [11]. The prevalence of infection in dogs is high and they represent urban domestic reservoirs for Leishmania spp. playing an essential role in disease epidemiology [12]. In Ethiopia, dogs and hyraxes are the main reservoir hosts for visceral and cutaneous leishmaniasis, respectively [9]. However, poor knowledge of canine leishmaniasis in the Ethiopian dog populations is available. As part of a study investigating the human VL outbreak in Libo Kemkem, Ethiopia, Alvar et al. [13] reported Leishmania DNA in the venous blood of two of the 40 asymptomatic dogs sampled. In northwest Ethiopia, where foci of human VL are common, Kalayou et al. [14] reported an overall seroprevalence of $L$. donovani infection of 27.7 and $14.8 \%$ in dogs, using direct agglutination test and Kala-azar detect rapid test, respectively. However, the $\operatorname{dog}$ (C. familiaris) population in Ethiopia is unknown and data on dog-related zoonotic diseases is scarce. Dog holding in big cities in Ethiopia has increased significantly in recent years along with increased urbanization. Dogs are mainly kept to protect owners and household properties. However, the attitude of keeping dogs as companion animals is also growing with the presently rising trend of urbanization and customizing western culture. In Addis Ababa, some people generate income by breeding and selling exotic dog breeds [15].

T. gondii can infect almost all warm-blooded animals and humans and can be transmitted through many different routes $T$. gondii is one of the most common parasites on earth, infecting as much as one-third of the world's human population [16]. The health burden of toxoplasmosis has been ranked among the highest of all parasitic diseases [17]. Humans are infected by $T$. gondii when they are consuming undercooked intermediate host meat harboring cysts, drinking oocyst-contaminated water by the final host (felids), and through congenital transmission. Only a small percentage of infected people exhibit clinical symptoms of the disease. $T$. gondii infection in pregnant women, on the other hand, can cause severe and disabling disease in the developing fetus $[16,18]$. Subclinical and clinical infections with T. gondii including fatal cases have been described in dogs [16]. 
Stray dogs and owned dogs with outdoor access play an important role in the epidemiology of $T$. gondii infection. This is due to the practice of feeding dogs on food types from various sources like garbage and food contaminated with soil. Like cats, dogs may also serve as a possible source of $T$. gondii infection in humans due to close contact [19]. Human T. gondii oocysts exposure through dogs can occur in connection with the mechanical transport of oocysts from the feces of cats by rolling in foul-smelling substances [20] thus serving as the parasite's environmental sentinel [18]. Dogs can become infected by the ingestion of $T$. gondii oocysts from cat feces or by the feeding habit of uncooked mutton (carnivorism). Antibodies to T. gondii were found worldwide in canine sera and viable $T$. gondii were also segregated from dogs' muscles and brain tissues [16, 18].

In Ethiopia, a meta-analytical study of IgG seroprevalence for $T$ gondii found a high pooled prevalence in animals $(87.72 \%$ in cats, $34.59 \%$ in small ruminants) and humans $(74.73 \%)$ with a high risk of sheep and goat reproductive problems and multiple human diseases [21]. However, no single published information is available about infection in dogs so far.

Toxoplasmosis in dogs is typically asymptomatic, and the clinical process in the respiratory and hepatic systems is often most noticeable when it occurs. Clinical cases of toxoplasmosis in cats are much more common than in dogs. A high proportion of clinical infections with $T$. gondii are caused by immunosuppressive chemotherapy [22]. However, neurological symptoms have also been identified [23, 24]. The clinical type may be due to the reactivation of latent infection associated with the immunosuppression caused by the canine distemper virus [25].

Good knowledge of the prevalence of $T$. gondii and Leishmania spp. in household dogs may aid in designing and implementing appropriate disease management strategies and could therefore benefit both animal and human health. Therefore, the present study was aimed to estimate the seroprevalence and associated risk factors of T. gondii and Leishmania spp. infections in dogs in Ambo, Bako, and Gojo towns of West Shewa Zone, Oromia, Ethiopia.

\section{Results}

\section{Seroprevalence}

The overall seroprevalence of $T$. gondii infection in dogs was found to be $82.86 \%$ (319/385, 95\% confidence interval [CI]: 78.71-86.49\%), and it was significantly different among the studied towns $\left(X^{2}=13.72, p=0.003\right)$. Of 385 dogs' sera tested for anti-Leishmania spp. antibodies, 356 (92.47, 95\% CI: 89.36-94.90\%) were seropositive with no statistically significant difference among the analyzed towns $\left(X^{2}=0.92, p=0.632\right)$. There was no statistically significant association between Leishmania spp. seropositivity and the independent variables evaluated in the study $(p>0.05)$ (Table 1).

Age-wise, the highest seroprevalence of $T$. gondii infection was found in adult dogs (84.35\%). The presence of cats and other domestic animals in the household was significantly associated with $T$. gondii seroprevalence (Table 2).

The study revealed that $82.58 \%(n=294)$ of the studied dogs were seropositive for both T. gondii and Leishmania spp. (Fig. 1). The Goodman and Kruskal's gamma statistics for correlation between the two binary outcome variables (Toxoplasma gondii and Leishmania spp. seropositivity) was weak and negative, which is not statistically significant (Goodman and Kruskal's gamma statistics value $=-0.137 p=0.591$ ).

\section{Risk factors \\ Toxoplasma gondii infection}

As indicated in Table 2 below, univariable logistic regression analysis showed that the likelihood of $T$. gondii seropositivity was 2.93 times higher in dogs of Bako town as compared to Ambo $(p=0.001)$. Similarly, the risk of $T$. gondii seropositivity in dogs was 1.80 times higher in households where other domestic animals are found $(p=0.032)$. The $T$. gondii seropositivity of dogs is significantly associated with the presence of cats in dogowning households (OR $=1.75$, 95\% CI: $1.00-3.06, p=$ 0.048).

In the multivariable logistic regression analysis, the risk of $T$. gondii infection in adult dogs was 2.71 times higher than in juvenile dogs $(p=0.043)$. The likelihood of getting seropositive dogs was 1.96 times high in

Table 1 The overall seroprevalence of T. gondii and Leishmania spp. infection in dogs of the study towns

\begin{tabular}{|c|c|c|c|c|c|}
\hline \multirow[t]{2}{*}{ Town } & \multirow{2}{*}{$\begin{array}{l}\text { No. } \\
\text { tested }\end{array}$} & \multicolumn{2}{|l|}{ T. gondii* } & \multicolumn{2}{|c|}{ Leishmania spp. } \\
\hline & & No. positive & $\%$ prevalence $(95 \% \mathrm{Cl})$ & No. positive & $\%$ prevalence $(95 \% \mathrm{Cl})$ \\
\hline Ambo & 169 & 127 & 75.15 (67.93-81.46) & 157 & 92.90 (87.93-96.28) \\
\hline Gojo & 68 & 59 & 86.76 (76.36-93.77) & 61 & 89.71 (79.93-95.76) \\
\hline Bako & 148 & 133 & 89.86 (83.83-94.22) & 138 & 93.24 (87.93-96.71) \\
\hline Overall & 385 & 319 & 82.86 (78.71-86.49) & 356 & 92.47 (89.36-94.90) \\
\hline
\end{tabular}

*Pearson $\mathrm{Chi}^{2}(3)=13.72, p=0.003, \mathrm{Cl}=$ Confidence interval 
Table 2 Results of logistic regression analysis of T. gondii prevalence and potential risk factors in selected districts of West Shewa zone, Ethiopia

\begin{tabular}{|c|c|c|c|c|c|c|c|}
\hline \multirow[t]{2}{*}{ Variable } & \multirow[t]{2}{*}{ Categories } & \multirow{2}{*}{$\begin{array}{l}\text { No. } \\
\text { tested }\end{array}$} & \multirow{2}{*}{$\begin{array}{l}\text { No. pos. (\% } \\
\text { prevalence) }\end{array}$} & \multicolumn{2}{|l|}{ Univariable } & \multicolumn{2}{|l|}{ Multivariable } \\
\hline & & & & OR $(95 \% \mathrm{Cl})$ & $P$ & OR $(95 \% \mathrm{Cl})$ & $P$ \\
\hline \multirow[t]{3}{*}{ Town } & Ambo & 169 & $127(75.15)$ & 1.0 & & 1.0 & \\
\hline & Gojo & 68 & $59(86.76)$ & $2.17(0.99-4.75)$ & 0.053 & & \\
\hline & Bako & 148 & $133(89.86)$ & $2.93(1.55-5.55)$ & $0.001^{*}$ & & \\
\hline \multirow[t]{2}{*}{ Altitude } & Highland ( $\geq 2100$ masl) & 237 & $186(78.48)$ & 1.0 & & 1.0 & \\
\hline & Midland (1600-2100 masl) & 148 & $133(89.86)$ & $2.43(1.31-4.51)$ & $0.005^{*}$ & $2.36(1.23-4.50)$ & $0.009^{*}$ \\
\hline \multirow[t]{4}{*}{ Age } & Juvenile & 27 & $19(70.37)$ & 1.0 & & 1.0 & \\
\hline & Adolescent & 77 & $63(81.82)$ & $1.89(0.69-5.20)$ & 0.214 & $2.42(0.83-7.03)$ & 0.105 \\
\hline & Geriatrics & 51 & $43(84.31)$ & $2.26(0.74-6.93)$ & 0.153 & $2.77(0.85-8.97)$ & 0.090 \\
\hline & Adult & 230 & $194(84.35)$ & $2.27(0.92-5.59)$ & 0.074 & $2.85(1.09-7.43)$ & $0.032^{*}$ \\
\hline \multirow[t]{2}{*}{ Sex } & Male & 293 & $239(81.57)$ & 1.0 & & 1.0 & \\
\hline & Female & 92 & $80(86.96)$ & $1.51(0.77-2.96)$ & 0.234 & $1.62(0.79-3.32)$ & 0.186 \\
\hline \multirow[t]{3}{*}{ Breed } & Exotic & 15 & $11(73.33)$ & 1.0 & & 1.0 & \\
\hline & Cross & 74 & $61(82.43)$ & $1.71(0.47-6.21)$ & 0.417 & & \\
\hline & Indigenous & 296 & $247(83.45)$ & $1.83(0.56-5.99)$ & 0.316 & & \\
\hline \multirow[t]{2}{*}{ Feeding } & Cooked & 103 & $83(80.58)$ & 1.0 & - & & \\
\hline & Raw animal products & 282 & $236(83.69)$ & $1.24(0.69-2.21)$ & 0.475 & & \\
\hline \multirow[t]{3}{*}{ Housing } & Indoor & 119 & $93(78.15)$ & 1.0 & & 1.0 & \\
\hline & Outdoor & 106 & 87 (82.08) & $1.28(0.66-2.48)$ & 0.463 & $1.44(0.71-2.90)$ & 0.309 \\
\hline & Mixed & 160 & 139 (86.88) & $1.85(0.98-3.48)$ & 0.056 & $1.55(0.79-3.03)$ & 0.203 \\
\hline \multirow[t]{2}{*}{ PODAHH } & No & 181 & $142(78.45)$ & 1.0 & & 1.0 & \\
\hline & Yes & 204 & $177(86.76)$ & $1.80(1.05-3.08)$ & $0.032^{*}$ & $1.94(1.10-3.42)$ & $0.022^{*}$ \\
\hline \multirow[t]{4}{*}{ Education of $\mathrm{HHH}$} & Secondary & 125 & $100(80.00)$ & 1.0 & & 1.0 & \\
\hline & Illiterate & 47 & $38(80.85)$ & $1.06(0.45-2.47)$ & 0.901 & $1.02(0.42-2.48)$ & 0.957 \\
\hline & Tertiary & 115 & $96(83.48)$ & $1.26(0.65-2.44)$ & 0.487 & $1.33(0.65-2.70)$ & 0.435 \\
\hline & Primary & 98 & 85 (86.73) & $1.63(0.79-3.39)$ & 0.187 & $1.50(0.70-3.19)$ & 0.298 \\
\hline \multirow[t]{2}{*}{ Living area/residence } & Urban & 341 & $280(82.11)$ & 1.0 & & & \\
\hline & Peri-urban & 44 & $39(88.64)$ & $1.70(0.64-4.49)$ & 0.285 & & \\
\hline \multirow[t]{2}{*}{ Presence of cats in the household } & No & 214 & $170(79.44)$ & 1.0 & & 1.0 & \\
\hline & Yes & 171 & $149(87.13)$ & $1.75(1.00-3.06)$ & $0.048^{*}$ & $1.65(0.92-2.95)$ & 0.094 \\
\hline \multirow[t]{2}{*}{ Family size of a dog-owning household } & $\leq 4$ & 114 & $93(81.58)$ & 1.0 & & & \\
\hline & $\geq 5$ & 271 & $226(83.39)$ & $1.13(0.64-2.01)$ & 0.666 & & \\
\hline \multirow[t]{4}{*}{$\mathrm{HHH}$} & Protestant & 248 & $199(80.24)$ & 1.0 & & & \\
\hline & Orthodox & 118 & $102(86.44)$ & $1.57(0.85-2.90)$ & 0.149 & & \\
\hline & Wagefeta & 8 & $7(87.50)$ & $1.72(0.21-14.34)$ & 0.614 & & \\
\hline & Muslim & 11 & $11(100.00)$ & - & - & & \\
\hline \multirow[t]{3}{*}{ Marital status of dog-owning $\mathrm{HHH}$} & Divorce & 25 & $20(80.00)$ & 1.0 & & & \\
\hline & Married & 343 & $283(82.51)$ & $1.18(0.43-3.27)$ & 0.751 & & \\
\hline & Single & 17 & $16(94.12)$ & $4.00(0.42-37.78)$ & 0.226 & & \\
\hline
\end{tabular}

* Statistically significant

PODAHH = presence of other domestic animals in the household, $\mathrm{HHH}=$ head of the household, $\mathrm{RHHH}=$ religion of the head of the household Full model $=\mathrm{HLX} 2=7.70, \mathrm{P}$-Value $=0.4632, \mathrm{Se}=99.37, \mathrm{Sp}=1.52, \mathrm{PPV}=82.98, \mathrm{NPV}, 33.33, \mathrm{ROC}=0.6993$

Best fitting model $=\mathrm{HLX} 2=5.89, \mathrm{P}$-Value $=0.6594, \mathrm{Se}=99.37, \mathrm{Sp}=3.03, \mathrm{PPV}=83.20, \mathrm{NPV}, 50.0, \mathrm{ROC}=0.6741$ 
households where other domestic animals are present than when they were absent $(p=0.021)$. Thus, the age of dogs and the presence of other domestic animals in the household were independent predictors of $T$. gondii seropositivity. On the other hand, altitude, sex, housing, and presence of cats in the household showed no significant association with $T$. gondii seropositivity in the final model $(p>0.05)$ (Table 2).

\section{Leishmania spp. infection}

All independent variables investigated were noncollinear with each other except district vs altitude $(\mathrm{r}=$ - 0.87). Based on the univariable logistic regression analysis, dogs' lifestyle, community type, and presence of cats in the household were variables that had $p<0.25$ and hence they were selected for the multivariable model. As a result, none of the risk factors investigated were independent predictors of Leishmania spp. infection $(\mathrm{p}>0.05)$ (Table 3).

\section{Discussion}

In this study, the seroprevalence and risk factors for $T$. gondii and Leishmania spp. infections were carried out on 385 dogs to understand the epidemiology and control measures for these infections in dogs and public health interventions. The current finding revealed that the seroprevalence in apparently healthy dogs for these two important zoonotic protozoon parasites was very high.

The $T$. gondii seroprevalence $(82.86 \%)$ in dogs corroborates well with the previous meta-analysis prevalence reports from Ethiopia in cats $(87.72 \%)$ but is higher than the reports in small ruminants $(34.59 \%)$ [21]. The high

Table 3 Results of logistic regression analysis of seroprevalence of Leishmania spp. infection and potential risk factors in selected districts of West Shewa zone, Ethiopia

\begin{tabular}{|c|c|c|c|c|c|c|c|}
\hline \multirow[t]{2}{*}{ Variable } & \multirow[t]{2}{*}{ Categories } & \multirow{2}{*}{$\begin{array}{l}\text { No. } \\
\text { tested }\end{array}$} & \multirow{2}{*}{$\begin{array}{l}\text { No. pos. (\% } \\
\text { prevalence) }\end{array}$} & \multicolumn{2}{|l|}{ Univariable } & \multicolumn{2}{|l|}{ Multivariable } \\
\hline & & & & OR $(95 \% \mathrm{Cl})$ & $\mathbf{P}$ & OR (95\% Cl) & $\mathbf{P}$ \\
\hline \multirow[t]{3}{*}{ Town/location } & Gojo & 68 & 61 (89.74) & 1.0 & & & \\
\hline & Ambo & 169 & 157 (92.90) & $1.50(0.56-3.99)$ & 0.415 & & \\
\hline & Bako & 148 & 138 (93.24) & $1.58(0.58-4.36)$ & 0.373 & & \\
\hline \multirow[t]{2}{*}{ Altitude } & Highland & 237 & $218(92.0)$ & 1.0 & & & \\
\hline & Midland & 148 & $138(93.2)$ & $1.20(0.54-2.66)$ & 0.649 & & \\
\hline \multirow[t]{4}{*}{ Age } & Adolescent & 77 & 70 (90.91) & 1.0 & & & \\
\hline & Geriatrics & 51 & 47 (92.16) & $1.18(0.33-4.24)$ & 0.805 & & \\
\hline & Adult & 230 & $213(92.61)$ & $1.25(0.50-3.15)$ & 0.631 & & \\
\hline & Juvenile & 27 & $26(96.30)$ & $2.6(0.30-22.17)$ & 0.382 & & \\
\hline \multirow[t]{2}{*}{ Sex } & Female & 92 & 85 (92.39) & 1.0 & & & \\
\hline & Male & 293 & 271 (92.49) & $1.01(0.42-2.46)$ & 0.975 & & \\
\hline \multirow[t]{3}{*}{ Breed } & Cross & 74 & $68(91.89)$ & 1.0 & & & \\
\hline & Indigenous & 296 & $274(92.57)$ & $1.10(0.43-2.82)$ & 0.844 & & \\
\hline & Exotic & 15 & $14(93.33)$ & $1.24(0.14-11.08)$ & 0.850 & & \\
\hline \multirow[t]{3}{*}{ Housing } & Outdoor & 106 & $95(89.62)$ & 1.0 & & 1.0 & \\
\hline & Indoor & 119 & 110 (92.44) & $1.42(0.56-3.56)$ & 0.461 & $1.19(0.46-3.07)$ & 0.719 \\
\hline & Mixed & 160 & 151 (94.38) & $1.94(0.78-4.86)$ & 0.156 & $1.74(0.69-4.41)$ & 0.243 \\
\hline \multirow[t]{2}{*}{ PODAHH } & Yes & 204 & 187 (91.67) & 1.0 & & 1.0 & \\
\hline & No & 181 & 169 (93.37) & $1.28(0.59-2.76)$ & 0.528 & & \\
\hline \multirow[t]{4}{*}{ Education of $\mathrm{HHH}$} & Secondary & 125 & $113(90.40)$ & 1.0 & & 1.0 & \\
\hline & Primary & 98 & $90(91.84)$ & $1.19(0.47-3.05)$ & 0.710 & & \\
\hline & Tertiary & 115 & $108(93.91)$ & $1.64(0.62-4.32)$ & 0.318 & & \\
\hline & Illiterate & 47 & $45(95.74)$ & $2.39(0.51-11.10)$ & 0.266 & & \\
\hline \multirow[t]{2}{*}{ Living area/residence } & Peri-urban & 44 & $38(96.36)$ & 1.0 & & 1.0 & \\
\hline & Urban & 341 & $318(93.26)$ & $2.18(0.84-5.70)$ & 0.111 & $2.05(0.77-5.47)$ & 0.152 \\
\hline \multirow[t]{2}{*}{ Presence of cats } & No & 214 & $194(90.65)$ & 1.0 & & 1.0 & \\
\hline & Yes & 171 & $162(94.74)$ & $1.86(0.82-4.19)$ & 0.137 & $1.72(0.75-3.93)$ & 0.197 \\
\hline
\end{tabular}




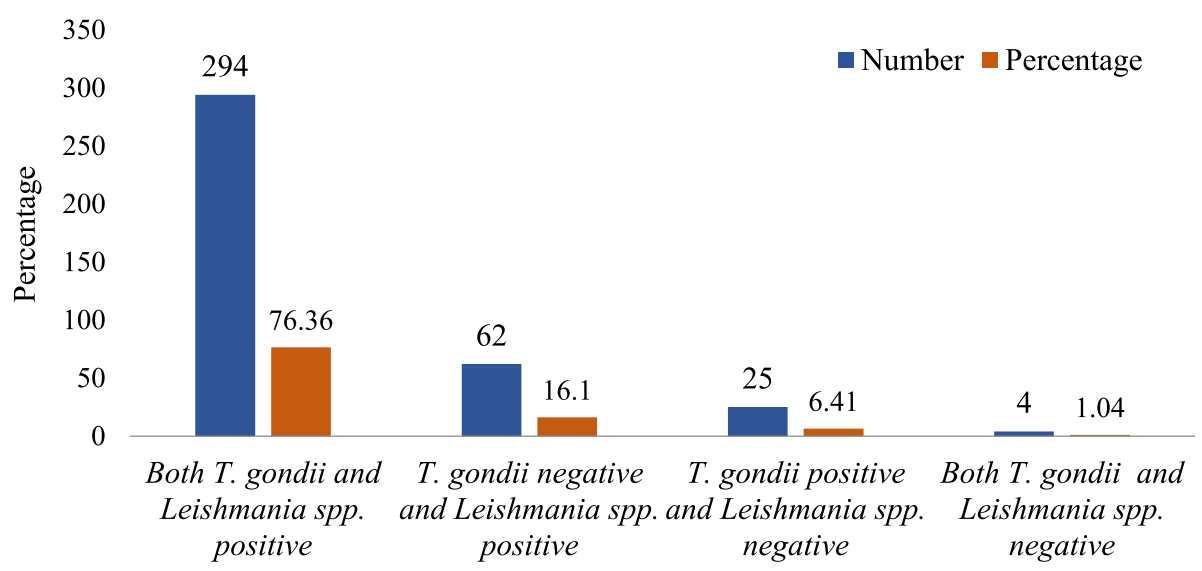

Types of infection

Fig. 1 The rate of co-infection of T. gondii and Leishmania spp. in dogs of the study towns

seroprevalence of $T$. gondii infection in this study indicates the widespread contamination of the urban environment with the parasite. Previous studies in seropositive sheep and goats [26], backyard chickens [27], and pigs [28] in central Ethiopia demonstrated the isolation of viable tissue cysts indicating that these animals might serve as a source of infection for dogs. In urban environments, dogs are likely to acquire $T$. gondii infection from infected prey such as birds, rodents, or tissue cysts from human leftover food available in the garbage [16, 29]. Moreover, the warm moist temperature and the high percentage of relative humidity in the studied towns might be favorable for the survival of the $T$. gondii oocysts [16].

Univariable logistic regression analysis showed a significant difference in the seroprevalence of $T$. gondii infection among the towns, i.e., it was high in Bako ( $p=$ 0.001) compared to Ambo town. This might indicate that climate considerably influences the risk of $T$. gondii exposure. The warm and moist environment coupled with the more abundance of cats [30] and the source of infection for dogs (cats, the meat of infected domestic or wild animals containing tissue cysts) in Bako town might explain the higher seroprevalence. It has been well documented that seroprevalence varies according to the density of cats and intermediate hosts [19], geographical location, and even within the same region from place to place. If cat-owning households there will be an ample chance to contaminate animals' farmlands, feed, and water [16]. The results showed an increase in seroprevalence from juvenile $(70.37 \%)$ to geriatrics $(84.31 \%)$ stage in agreement with the previous report [31]; the odds of acquiring $T$. gondii infection in adult dogs is nearly 2.71 times higher as compared to juvenile dogs $(p=0.043)$. As the age of dogs increases the likelihood of acquiring T. gondii infection from the environment increases i.e., postnatal/horizontal infection is the main route of infection [16, 32-36]. Moreover, the lifelong persistence of IgG antibodies once infected might also add to the high prevalence in older dogs [16].

Very high seroprevalence of Leishmania spp. infection was observed in the present study $(92.47 \%)$ in contrast to Rohousova et al. [37] which reported relatively lower seropositivity of $55.9 \%(19 / 34)$ and PCR positivity of $5.9 \%(2 / 34)$ in dogs of Northwestern Ethiopia (Oromia). However, in that Ethiopian region, no data are available on the competent vector populations present, so we cannot exclude that dogs might be the preferential hosts for the sand fly species present in this area. A complex relationship between hosts, parasites, and sand fly vectors, makes the transmission of Leishmania spp. quite intricate as also suggested by the so-called paradox of Cyprus where a high seroprevalence for $L$. infantum in the dog population does not correspond to leishmaniasis cases and seroprevalence in humans; two transmission cycles seem to run in parallel in Cyprus: in dogs with $L$. infantum and humans with $L$. donovani [38]. The expansion of agricultural activities increased urbanization, the abundance of reservoir hosts (e.g., hyraxes) and the biological vectors (sandflies) adaptation of the parasites and vectors might also contribute to the high seroprevalence $[9,14,39]$. Moreover, the weak health infrastructure and poor or absence of disease and vector control programs in dogs and humans of the current study areas, are additional contributing factors.

Although Leishmania infection of dogs ranging from 60 to $80 \%$ has been reported in endemic areas [40], the current seroprevalence was much higher and less related to the factors considered in this study compared to Toxoplasma since no statistically significant variations were detected among the three cities. This might suggest that infection transmission through a vector such as sand flies for Leishmania spp. might be related to environmental, structural, and human factors similar in the 
three cities considered in this study. Moreover, vectorborne diseases are influenced by environmental changes and socioeconomic factors such as sanitary conditions, malnutrition, population movement, or poor housing. A recent study in Nepal for human leishmaniosis in endemic districts found that houses with natural floors increased the risk of infection by eightfold, walls made from straw, leaves, and/or bamboos increased by threefold, walls with cracks, especially in the bedroom, increased by threefold and proximity to a livestock shed increased the risk by fourfold [41]. Anthropogenic factors tend to reorient the composition and behavior of sand fly vectors. To date, there are at least 50 different sand fly species transmitting leishmaniases [42].

In this study, contrary to our expectation, there was no significant difference in the seroprevalence of $T$. gondii and Leishmania spp. infections between indoor and outdoor kept dogs. In Ethiopia, exotic and crossbred dogs are mostly kept indoors while indigenous dogs live outdoors. However, the infection rate of both parasites was considerably high in both canine populations. For $T$. gondii infection this might be explained by the fact that both populations are fed with food waste and raw meat instead of commercial or adequately cooked food. For Leishmania spp. infection, the shelters for dogs are not built to avoid sandflies access and indoor conditions cannot assure the absence of the vectors. Due to the complex relationship between human, animal hosts, parasites, and sand fly vectors, the transmission of Leishmania spp. is intricate. Nevertheless, the absence of a statistically significant association between seroprevalence of Leishmania spp. and potential risk factors considered in this study should prompt further studies in the future to identify the risk factors.

There was a high percentage of concurrent infection of dogs with $T$. gondii and Leishmania spp. (82.58\%) as well as the absence of significant difference in the seroprevalence of the two parasites across altitudes, sex, breeds, housing and living areas/residence (urban vs peri-urban). These might suggest the ubiquitous nature of the parasites and that these factors have a similar risk of infection as reported by other researchers elsewhere $[35,38,39,43]$. Besides, the lack of association of T. gondii seropositivity with breed and sex of dogs might have probably be overshadowed by the high exposure to the parasite at a very young age [30,33]. In agreement with the present study, Kalayou et al. [14] also reported the absence of a significant association between sex, housing, and place of residence and $L$. donovani seroprevalence in dogs of northwest Ethiopia.

The study identified widespread T. gondii and Leishmania spp. infections in the canine population along with the contributing risk factors for the transmission. Such information may serve in the efforts to minimize the risk of zoonosis in humans. The asymptomatically infected dogs living together or very close to humans identified in the current study might maintain Leishmania spp. and T. gondii parasites to other animals and humans. Thus, because of the high seroprevalence and the poor or non-existent veterinary medical care for dogs, high HIV/AIDS prevalence, the overall inadequate personal hygiene, and environmental sanitation in the studied towns, these zoonotic parasites might be of great public health concern since asymptomatically infected dogs might be the source of infection for humans [36].

The limitations of this cross-sectional survey include the failure to collect data on clinical manifestations of dogs to relate it with seropositivity. Nevertheless, the findings for these zoonotic parasites indicate the magnitude of infections and that dogs might be an important reservoir posing potential health risks for animals and humans.

To the best of the knowledge of the authors, this is the first report of seroprevalence of $T$. gondii infection as well as co-infection of $T$. gondii and Leishmania spp. from household dogs in Ethiopia.

\section{Conclusions}

The results showed very high infection rates for both parasites and the simultaneous presence of $T$. gondii and Leishmania spp. in dogs suggesting the widespread nature of these parasites in the urban environments and the big potential risk of transmission to humans and other animals. The age of dogs and the presence of other domestic animals in households are predictors of T. gondii seropositivity. None of the investigated variables are independent predictors of Leishmania spp. seropositivity. Further studies to isolate, identify the genotype and virulence of the parasites, preferably from clinical cases, as well as the contribution of dogs in the transmission of the infections to humans along with hygienic measures and educational campaigns, is imperative.

\section{Materials and methods}

\section{Study design and areas}

A cross-sectional household survey was undertaken in Ambo, Bako, and Gojo towns of West Shewa Zone, Oromia Regional State, from January 2015 to June 2017. Ambo, Bako, and Gojo towns are the administrative centers of Ambo, Bako Tibe, and Jeldu districts, respectively. Table 4 shows the location, latitude, longitude, temperature, rainfall, elevation, and the human population of the study towns. The three towns have bimodal rainfall characterized by a short rainy season from February to May, and the large rainy season is from July to September. The dry season extends from October to January [43]. 
Table 4 Description of the study towns

\begin{tabular}{llll}
\hline Descriptions & Study towns & & \\
\cline { 2 - 4 } & Ambo & Bako & Gojo \\
\hline Distance from Addis Ababa & $114 \mathrm{~km}$ & $260 \mathrm{~km}$ & $120 \mathrm{~km}$ \\
Latitude and longitude & $8^{\circ} 59^{\prime} \mathrm{N} 37^{\circ} 51^{\prime} \mathrm{E}$ & $9^{\circ} 08^{\prime} \mathrm{N} 37^{\circ} 03^{\prime} \mathrm{E}-9^{\circ} 08^{\prime} \mathrm{N} 37^{\circ} 03^{\prime} \mathrm{E}$ & $9.26^{\prime} \mathrm{N} 38.09 \mathrm{E}$ \\
Elevation (meters above sea level) & 2101 & 1743 & 2905 \\
Average annual temperature $\left({ }^{\circ} \mathrm{C}\right)$ & 22 & 19.7 & 20 \\
Average annual rainfall $(\mathrm{mm})$ & 900 & 1281 & 2500 \\
Total human population $[44]$ & 74,843 & 18,641 & 14,794 \\
\hline
\end{tabular}

\section{Study population}

Stray dogs were excluded from the present study. Thus, owned dogs above three months of age found in the three towns were the study population.

\section{Animals and samples}

Domestic /owned/ dogs (C. familiaris) from each randomly selected "Gotes" (Gote is a subdivision of Kebele containing 20-30 households) were sampled from house to house. "Kebele" refers to the smallest administrative unit of a town. The veterinary service provided to the dogs is quite inadequate and consequently, the vast majority of the studied dogs received no rabies vaccination and /or other treatments. Dogs above three months of age were sampled to avoid transcolostral antibodies [16]. The age of dogs ranged from 3 to 168 months, with an average value of 33 months.

\section{Sample size and sampling technique}

Since there is no previous $T$. gondii seroprevalence study in Ethiopia, 50\% expected prevalence, 5\% desired absolute precision, and $95 \% \mathrm{CI}$ were used to calculate the required sample size using the formula: $N=1.96^{2}$ pexp (1$\left.\mathrm{p}_{\text {exp }}\right) / \mathrm{d}^{2}$ [45], where $\mathrm{n}=$ required sample size, $\mathrm{p}=\mathrm{ex}$ pected prevalence $\mathrm{d}=$ desired absolute precision. Therefore, the calculated sample size was 384 . There was no accessible data on the dog population in the three towns. Thus, it was assumed that the population of dogs in the towns is evenly distributed. A multi-stage sampling procedure was employed to select households for this study. There are three, two, and one Kebele in Ambo, Bako, and Gojo towns respectively. From each "Kebeles," four "Gotes" were randomly selected using the list of Gotes in each Kebeles (sampling frame) provided by local administrators. The index household in a Gote was randomly selected and subsequent households were surveyed door to door.

\section{Blood sample collection}

Five milliliters of whole blood was aseptically collected from each dog's cephalic vein using a plain vacutainer tube. The blood samples were kept at room temperature and allowed to clot in a slanted position in a cool place and serum was separated by centrifugation at 3000 RPM for $10 \mathrm{~min}$, transferred into cryovials, labeled, and stored at $-20^{\circ} \mathrm{C}$ until the laboratory assay was carried out.

\section{Questionnaire survey}

A pre-tested structured questionnaire was prepared and administered to dog owners during blood sample collection. The close-ended questions asked include sex (male, female), breed (exotic, cross, indigenous), housing system (indoor, outdoor, mixed), feeding (cooked animal products, household leftover, raw animal products), presence of other domestic animals in the household (cattle, sheep, goats, horse, mule, donkey, cats, chicken), educational level of dog owner (illiterate, primary, secondary, tertiary), presence of cat/s in the household (yes, no), living area/residence (urban, peri-urban), marital status (single, married, divorced), the religion of the head of the household (Protestant, Orthodox, Waqefeta, Muslim), and family size of the dog-owning household $(\leq 4, \leq 5)$, The age of dogs was categorized as a juvenile (6 weeks to 6 months), young (6 months to 18 months), adult (18 months to 7 years), and geriatric (greater than 7 years) based on owners information [46].

\section{Laboratory test}

Sera samples were transported to the National Animal Health and Diagnostic Center (NAHDIC) in ice packs and stored at $-20^{\circ} \mathrm{C}$ until assayed. T. gondii IgG antibody was determined from each sample using a commercially available Direct Agglutination Test (DAT) kit (Toxo screen DA, biomerieux ${ }^{\circ}$, France) following the manufacturer's instructions. Sera were assayed at a screening dilution of $1 / 40$ and $1 / 4000$ to avoid the falsenegative results that might occur at low dilutions when using sera with high antibody titers. T. gondii infection was diagnosed when a serum sample gave a positive reaction indicated by a clear agglutination above half of the well at a dilution of 1:40 or 1: 4000 or both. Sedimentation of antigen at the bottom of the well was considered as a negative result. Positive and negative controls were included in each test. All the collected 
serum samples were tested for the presence of antibodies against Leishmania spp. following the protocol of the manufacturer of the indirect ELISA kit (VetLine, NovaTec Immundiagnostica GmbH, Germany). According to the manufacturer, the sensitivity and specificity of the kit are $>98 \%$.

\section{Data analysis}

The findings of the questionnaire survey and laboratory data were entered into Microsoft Excel Spreadsheet. Coded data was transferred into STATA version 14.0 for Windows (Stata Corp. College Station, TX, USA). The association of the seroprevalence with putative risk factors was first statistically analyzed using Pearson's Chisquare test. Seroprevalence figures by DAT (for T. gondii infection) and ELISA (for Leishmania spp. infection) were considered as dependent variables. Age, sex, breed, feeding, housing, town, altitude, residence place, presence of cats, presence of other domestic animals, family size, marital status, and religion were the independent/ explanatory variables investigated. Univariable and multivariable logistic regressions were used to identify the predictors of $T$. gondii seropositivity. Non-collinear variables with $p$-value $<0.25$ in univariable analysis were further analyzed using multivariable logistic regression to identify risk factors of seropositivity and obtain adjusted odds ratios with $95 \%$ CI. The 95\% confidence level for the subgroup and overall prevalence values were calculated using the exact binomial test. Goodman and Kruskal's gamma statistics was used to see the correlation between the binary outcomes (T. gondii and Leishmania spp. Serostatus). Differences were considered statistically significant at $p<0.05$.

\section{Acknowledgments}

The authors would like to thank Ambo University for financing the project on "surveillance of dog-related zoonoses". The Italian National Reference Center for Toxoplasmosis at the Istituto Zooprofilattico Sperimentale della Sicilia A. Mirri, Italy, and partial financial support to Maria Vitale grant No. RF 2007/RC from the Italian Ministry of Health deserves special thanks. We are also grateful for the cooperation of owners of dogs and for allowing blood samples from their dogs. The National Animal Health and Disease Investigation Center (NAHDIC) at Sebeta is highly acknowledged for allowing the laboratory facilities.

\section{Authors' contributions}

EZG designed the study, analyzed the data, and drafted the manuscript. EJS, GKT, SSE, and LMM participated in the field questionnaire survey, blood sample collection, and enrichment of the drafted manuscript. AT contributed to the laboratory testing of sera samples, interpretation of results, and enriched the manuscript. MV and V di M Lo P participated in the study design and edition of the article. All authors have read and approved the manuscript.

\section{Funding}

This work was supported by Ambo University and the Italian National Reference Center for Toxoplasmosis at the Istituto Zooprofilattico Sperimentale della Sicilia A. Mirri, Italy (grant No. RF 2007/RC).

\section{Availability of data and materials}

The datasets used and/or analyzed during the current study are available from the corresponding author on reasonable request.

\section{Declarations}

\section{Ethics approval and consent to participate}

The Research and Ethics Review Committee of Ambo University approved the experimental protocols. The study protocols complied with the guidelines of the Research and Ethical Review Committee of Ambo University and that of the guideline of the Animal Research Reporting for In Vivo Experiments. Blood samples were collected by the researchers (veterinarians) after getting informed consent from the owners of the dogs. All efforts were made to minimize animal suffering during sample collection. As an incentive, all dogs were vaccinated for rabies, and antiparasitic drugs were administered for control of internal and external parasites. Oral informed consent was obtained from all people who participated in the study.

\section{Consent for publication}

Not applicable.

\section{Competing interests}

The authors declare that they have no competing interests.

\section{Author details}

${ }^{1}$ Department of Veterinary Sciences, Ambo University, School of Veterinary Medicine, P. O. Box 19, Ambo, Ethiopia. ${ }^{2}$ Department of Veterinary Laboratory Technology, Ambo University, School of Veterinary Medicine, P. O. Box 19, Ambo, Ethiopia. ${ }^{3}$ National Animal Health Diagnostic and Investigation Center, P. O. Box 04, Sebeta, Ethiopia. ${ }^{4}$ Istituto Zooprofilattico sperimentale della Sicilia "A. Mirri", Area Territoriale, Barcellona Pozzo di Gotto, Italy. ${ }^{5}$ Laboratory of Genetics of Microorganisms, Istituto

Zooprofilattico Sperimentale of Sicily, Via Gino Marinuzzi 3, 90129 Palermo, Italy.

Received: 13 February 2021 Accepted: 5 August 2021

Published online: 25 August 2021

\section{References}

1. Aguirre AA, Longcore T, Barbieri M, Dabritz H, Hill D, Klein PN, et al. The one health approach to toxoplasmosis: epidemiology, control, and prevention strategies. Ecohealth. 2019;16(2):378-90. https://doi.org/10.1007/s10393-01901405-7.

2. Moncaz A, Faiman R, Kirstein O, Warburg A. Breeding sites of Phlebotomus sergenti, the sand fly vector of cutaneous leishmaniosis in the Judean Desert. PLoS Negl Trop Dis. 2012;6(7):e1725. https://doi.org/10.1371/journal. pntd.0001725.

3. Alvar J, Vélez ID, Bern C, Herrero M, Desjeux P, Cano J, et al. Leishmaniosis worldwide and global estimates of its incidence. PLoS One. 2012;7(5): e35671. https://doi.org/10.1371/journal.pone.0035671.

4. Kassahun A, Sadlova J, Dvorak V, Kostalova T, Rohousova I, Frynta D, et al. Detection of Leishmania donovani and L. tropica in Ethiopian wild rodents. Acta Trop. 2015;145:39-44. https://doi.org/10.1016/j.actatropica.2015.02.006

5. WHO: Control of the leishmaniases: report of a meeting of the WHO Expert Committee on the Control of Leishmaniases. In: World Health Organ Tech Rep Ser. vol. 949. Geneva; 2010: 1-186.

6. Kaszak I, Planellas M, Dworecka-Kaszak B. Canine leishmaniosis - an emerging disease. Ann Parasitol. 2015:61(2):69-76.

7. Maia C, Cardoso L. Spread of Leishmania infantum in Europe with dog traveling. Vet Parasitol. 2015;213(1-2):2-11. https://doi.org/10.1016/j.vetpar.2 015.05.003 Epub 2015 May 14.

8. Reguera RM, Morán M, Pérez-Pertejo Y, García-Estrada C, Balaña-Fouce R. Current status on prevention and treatment of canine leishmaniasis. Vet Parasitol. 2016;227:98-114. https://doi.org/10.1016/j.vetpar.2016.07.011 Epub 2016 Jul 12

9. Gebremichael D. Zoonotic impact and epidemiological changes of leishmaniosis in Ethiopia. Open Vet J. 2018;8(4):432-40. https://doi.org/1 0.4314/ovj.v8i4.13.

10. Hailu A, Dagne DA, Boelaert M: Leishmaniosis. In: Neglected Tropical Diseases-Sub-Saharan Africa. edn.: Springer; 2016: 87-112. 
11. Veras PST, Fraga DBM, Solcà M, Guedes CES: New advances in the diagnosis of canine visceral leishmaniosis. In: Leishmaniosis - trends in epidemiology, diagnosis, and treatment. edn.; 2014.

12. Moshfe A, Mohebali M, Edrissian G, Zarei Z, Akhoundi B, Kazemi B, et al. Canine visceral leishmaniosis: asymptomatic infected dogs as a source of $L$. infantum infection. Acta Trop. 2009;112(2):101-5. https://doi.org/10.1016/j.a ctatropica.2009.07.004

13. Alvar J, Bashaye S, Argaw D, Cruz I, Aparicio P, Kassa A, et al. Kala-azar outbreak in Libo Kemkem, Ethiopia: epidemiologic and parasitologic assessment. Am J Trop Med Hyg. 2007;77(2):275-82. https://doi.org/10.42 69/ajtmh.2007.77.275.

14. Kalayou S, Tadelle H, Bsrat A, Abebe N, Haileselassie M, Schallig H. Serological evidence of Leishmania donovani infection in apparently healthy dogs using direct agglutination test (DAT) and rk39 dipstick tests in Kafta Humera, north-West Ethiopia. Transbound Emerg Dis. 2011;58(3):255-62. https://doi.org/10.1111/j.1865-1682.2011.01209.x.

15. Anonymous. https://t.me/Ethio_kennel..Accessed 16.4.21.

16. Dubey J. Toxoplasmosis in animals and humans. 2nd ed. Boca Raton: CRC Press; 2010.

17. Djurkovic-Djakovic O, Dupouy-Camet J, Van der Giessen J, Dubey JP Toxoplasmosis: an overview from a one health perspective. Food Waterborne Parasitol. 2019;15:e00054. https://doi.org/10.1016/j.fawpar.2019. e00054.

18. El Behairy A, Choudhary S, Ferreira L, Kwok O, Hilali M, Su C, et al. Genetic characterization of viable toxoplasma gondii isolates from stray dogs from Giza, Egypt. Vet Parasitol. 2013;193(1-3):25-9. https://doi.org/10.1016/j.vetpa r.2012.12.007.

19. Oi M, Yoshikawa S, Maruyama S, Nogami S. Comparison of toxoplasma gondii seroprevalence in shelter cats and dogs during 1999-2001 and 2009-2011 in Tokyo, Japan. PLoS One. 2015;10(8):e0135956. https://doi.org/1 0.1371/journal.pone.0135956.

20. Frenkel JK, Lindsay DS, Parker BB, Dobesh M. Dogs as possible mechanical carriers of toxoplasma, and their fur as a source of infection of young children. Int J Infect Dis. 2003;7(4):292-3. https://doi.org/10.1016/S1201-9712 (03)90112-3

21. Gebremedhin EZ, Tadesse G. A meta-analysis of the prevalence of toxoplasma gondii in animals and humans in Ethiopia. Parasit Vectors. 2015; 8(1):291. https://doi.org/10.1186/s13071-015-0901-7.

22. Calero-Bernal R, Gennari SM. Clinical Toxoplasmosis in Dogs and Cats: An Update. Front Vet Sci. 2019;6(54):1-9. https://doi.org/10.3389/fvets.2019. 00054.

23. Patitucci AN, Alley MR, Jones BR, Charleston WA. Protozoal encephalomyelitis of dogs involving Neospora caninum and toxoplasma gondii in New Zealand. N Z Vet J. 1997;45(6):231-5. https://doi.org/10.1080/ 00480169.1997 .36035$.

24. Migliore S, La Marca S, Stabile C, Di Marco Lo Presti V, Vitale M. A rare case of acute toxoplasmosis in a stray dog due to infection of T. gondii clonal type I: public health concern in urban settings with stray animals? BMC Vet Res. 2017;13(1):249.

25. Dubey J, Carpenter J, Topper M, Uggla A. Fatal toxoplasmosis in dogs. J Am Anim Hosp Assoc. 1989;25:659-64.

26. Gebremedhin EZ, Abdurahaman M, Tessema TS, Tilahun G, Cox E, Goddeeris $B$, et al. Isolation and genotyping of viable toxoplasma gondii from sheep and goats in Ethiopia destined for human consumption. Parasit Vectors. 2014:7(1):425. https://doi.org/10.1186/1756-3305-7-425.

27. Gebremedhin EZ, Tesfamaryam G, Duguma R, Tilahun G, Di Marco V, Vitale M. Majority of T. gondii seropositive chickens (Gallus domesticus) in Central Ethiopia carries the infective parasite. Acta Vet Scand. 2014;56(1):60.

28. Gebremedhin E, Kebeta M, Asaye M, Ashenafi H, Marco Vd, Vitale M: Bioassay of Toxoplasma gondii from apparently healthy pigs slaughtered in Addis Ababa abattoir, Ethiopia. J Veet Sci Technol 2015, 6(5).

29. Meireles L, Galisteo A Jr, Pompeu E, Andrade H Jr. Toxoplasma gondii spreading in an urban area evaluated by seroprevalence in free-living cats and dogs. Tropical Med Int Health. 2004;9(8):876-81. https://doi.org/10.1111/ j.1365-3156.2004.01280.x

30. Gebremedhin EZ, Sarba EJ, Getaneh AM, Tola GK, Endale SS, Marami LM. Demography and determinants of dog and cat ownership in three towns of west Shoa zone, Oromia region, Ethiopia. BMC Vet Res. 2020;16(1):481. https://doi.org/10.1186/s12917-020-02699-4.

31. Lopes MG, Mendonça IL, Fortes KP, Amaku M, HdFJ P, Gennari SM. Presence of antibodies against toxoplasma gondii, Neospora caninum, and Leishmania infantum in dogs from Piauí. Rev Bras Parasitol Vet. 2011;20(2):111-4. https:// doi.org/10.1590/S1984-29612011000200004

32. Lopes AP, Granada S, Oliveira AC, Brancal H, Dubey JP, Cardoso L, et al. Toxoplasmosis in dogs: first report of toxoplasma gondii infection in any animal species in Angola. Pathog Glob Health. 2014;108(7):344-6. https:// doi.org/10.1179/2047773214Y.0000000160.

33. Kamani J, Mani AU, Kumshe HA, Dogo Gl, Yidawi JP, Pauline DK, et al. Serosurvey for toxoplasma gondii in dogs in Maiduguri, Borno state, Nigeria. J Infect Dev Ctries. 2010;4(01):015-8.

34. Langoni H, Fornazari F, RCd S, Monti ET, Villa FB. Prevalence of antibodies against toxoplasma gondii and Neospora caninum in dogs. Braz J Microbiol. 2013;44(4):1327-30. https://doi.org/10.1590/S1517-83822013000400043.

35. Lin D-S. Seroprevalences to toxoplasma gondii in privately-owned dogs in Taiwan. Prev Vet Med. 1998;35(1):21-7. https://doi.org/10.1016/S01675877(97)00090-1.

36. Moré G, Venturini MC, Pardini L, Unzaga JM: Toxoplasma. In: Parasitic Protozoa of Farm Animals and Pets. edn. Edited by Florin-Christensen M, Schnittge L. Switzerland: Springer, Cham.; 2018: 149-168.

37. Rohousova I, Talmi-Frank D, Kostalova T, Polanska N, Lestinova T, Kassahun A, et al. Exposure to Leishmania spp. and sand flies in domestic animals in northwestern Ethiopia. Parasit Vectors. 2015;8(1):360.

38. Mazeris A, Soteriadou K, Dedet JP, Haralambous C, Tsatsaris A, Moschandreas J, et al. Leishmaniases and the Cyprus paradox. Am J Trop Med Hyg. 2010:82(3):441-8. https://doi.org/10.4269/ajtmh.2010.09-0282.

39. Leta S, Dao THT, Mesele F, Alemayehu G. Visceral leishmaniosis in Ethiopia: an evolving disease. PLoS Negl Trop Dis. 2014;8(9):e3131. https://doi.org/1 0.1371/journal.pntd.0003131.

40. Solano-Gallego L, Morell P, Arboix M, Alberola J, Ferrer L. Prevalence of Leishmania infantum infection in dogs living in an area of canine leishmaniosis endemicity using PCR on several tissues and serology. J Clin Microbiol. 2001;39(2):560-3. https://doi.org/10.1128/JCM.39.2.560-563.2001.

41. Younis LG, Kroeger A, Joshi AB, Das ML, Omer M, Singh VK, et al. Housing structure including the surrounding environment as a risk factor for visceral leishmaniosis transmission in Nepal. PLoS Negl Trop Dis. 2020;14(3): e008132. https://doi.org/10.1371/journal.pntd.0008132.

42. Hong A, Zampieri RA, Shaw JJ, Floeter-Winter LM, Laranjeira-Silva MF. One health approach to leishmaniases: understanding the disease dynamics through diagnostic tools. Pathogens. 2020;9(10):809. https://doi.org/10.3390/ pathogens9100809.

43. CSA: The Federal Democratic Republic of Ethiopia, Agricultural Sample Survey: Report on Livestock and Livestock Characteristics. In.; 2015: 27.

44. CSA: Summary and statistical report of the 2007 Population and housing census. Population size by age and sex. In. Edited by commission FdroEpc Addis Ababa,Ethiopia; 2008: e8-12.

45. Thrusfield M: Veterinary epidemiology; describing disease occurrence, 3rd edition edn: Blackwell publishing; 2005

46. Kiflu B, Alemayehu H, Abdurahaman M, Negash Y, Eguale T. Salmonella serotypes and their antimicrobial susceptibility in apparently healthy dogs in Addis Ababa, Ethiopia. BMC Vet Res. 2017;13(1):134. https://doi.org/10.11 86/s12917-017-1055-y

\section{Publisher's Note}

Springer Nature remains neutral with regard to jurisdictional claims in published maps and institutional affiliations.

Ready to submit your research? Choose BMC and benefit from

- fast, convenient online submission

- thorough peer review by experienced researchers in your field

- rapid publication on acceptance

- support for research data, including large and complex data types

- gold Open Access which fosters wider collaboration and increased citations

- maximum visibility for your research: over $100 \mathrm{M}$ website views per year

At BMC, research is always in progress.

Learn more biomedcentral.com/submission 